This item was submitted to Loughborough's Research Repository by the author.

Items in Figshare are protected by copyright, with all rights reserved, unless otherwise indicated.

\title{
Participatory action research: a winning strategy for KM
}

PLEASE CITE THE PUBLISHED VERSION

http://dx.doi.org/10.1108/13673270910997196

PUBLISHER

(c) Emerald Group Publishing Ltd

\section{VERSION}

SMUR (Submitted Manuscript Under Review)

\section{LICENCE}

CC BY-NC-ND 4.0

\section{REPOSITORY RECORD}

Ragsdell, Gillian. 2019. "Participatory Action Research: A Winning Strategy for KM". figshare. https://hdl.handle.net/2134/14818. 
This item was submitted to Loughborough's Institutional Repository (https://dspace.lboro.ac.uk/) by the author and is made available under the following Creative Commons Licence conditions.

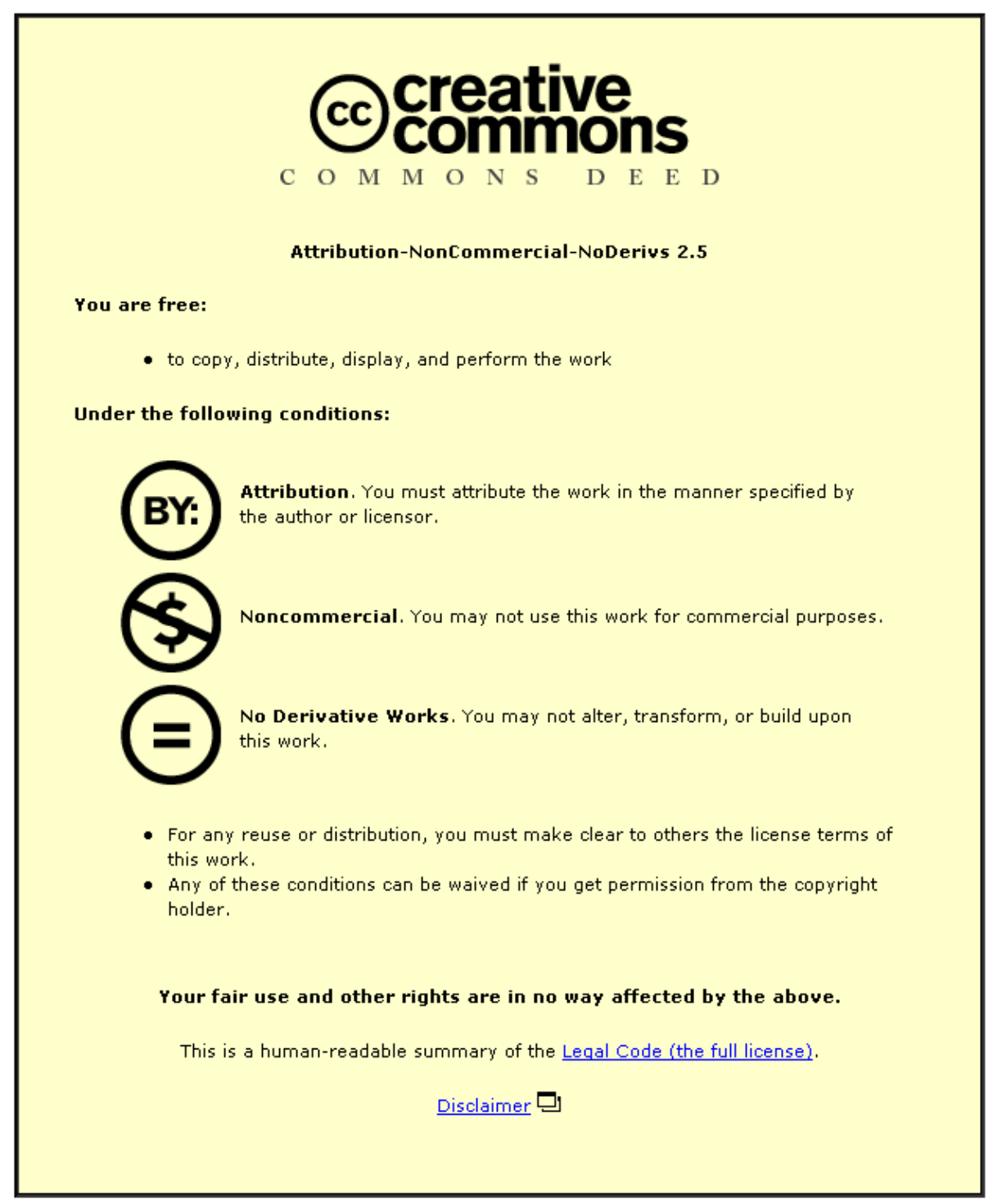

For the full text of this licence, please go to: http://creativecommons.org/licenses/by-nc-nd/2.5/ 


\section{Dr Gillian Ragsdell}

Affiliation: Loughborough University

e-mail: $\quad$ g.ragsdell@lboro.ac.uk

Telephone: 00441509223082

Address: $\quad$ Department of Information Science, Loughborough University, Loughborough, Leics. LE11 3TU. UK

\section{Brief Biography:}

Dr Gillian Ragsdell is a Lecturer in Knowledge Management in the Department of Information Science at Loughborough University, United Kingdom. She combines her industrial experience with her academic interests to build on the relationship between the theory and practice of knowledge management. Her origins in systems thinking and creative problem solving have proved particularly effective in the generation and sharing of knowledge. Action research projects have taken her into various organisations; recent examples include organisations from the voluntary sector, the water industry and the military. 


\title{
Participatory Action Research: A winning strategy for KM
}

\begin{abstract}
Purpose - This paper aims to contribute to an emerging debate centred on the ways in which knowledge management (KM) might be effectively researched and, in turn, how KM practice might be improved.

Design/methodology/approach - Burrell and Morgan's (1979) paradigms are used to set the scene and to highlight the changing focus in three closely related areas - research per se, the $\mathrm{KM}$ movement and KM research. Albeit the changes are not occurring simultaneously, the general trend in these areas is similar i.e. there is a move from a functionalist stance to one based on interpretivism. Next, case study research and participatory action research (PAR) are introduced as examples of research approaches that, respectively, tend to reflect the functionalist and interpretivist paradigms. Then there is an analysis of a KM research project from each of these approaches. Each research project is analysed with respect to five dimensions and in terms of the benefits that the organisation gained for its KM practice. The analysis is used as a vehicle to propose that PAR makes a significant contribution in tackling some of the acknowledged obstacles to effective KM practice.

Findings - The characteristics of PAR would appear to complement KM activities. As such, PAR is put forward as a strategy for meaningfully researching KM while, simultaneously, improving KM practice.

Originality/Value - This paper accelerates discussion about how KM research is undertaken and demonstrates how the synergy between PAR and KM can be exploited for the benefit of KM researchers and practitioners.
\end{abstract}

Keywords - Knowledge Management; Research Strategy; Participatory Action Research Paper Type - Research paper

\subsection{Introduction}

This paper aims to contribute to an emerging debate centred on the ways in which knowledge management (KM) might be effectively researched and, in turn, how KM practice might be improved. Building on the work of Kane et al (2006) where an ethnographic approach to KM research was suggested as a way of dealing with the increasing emphasis on tacit knowledge, this paper moves the debate on by drawing attention to the use of participatory action research (PAR) for KM research. It is argued, herein, that PAR holds the potential to simultaneously 'add value' to both the academic and practical arenas.

The argument is developed as follows. The scene is set by acknowledging that, in keeping with the general KM movement, there has been a noticeable shift from functionalist approaches to KM research, to ones that adopt a more interpretivist stance. Continuing with the use of sociological paradigms to frame the discussion, the oft-seen tension between functionalism and interpretivism in KM research is highlighted and a call for coherence between research strategy and its practice is made. A case study approach to research and PAR are next introduced as examples of approaches that are underpinned by the different paradigms. There is particular emphasis on PAR's client-researcher relationship and its intention to bring improvement to an organisational setting. Two KM research projects recently undertaken by the author are then used as vehicles to illustrate the functionalistinterpretivist divide. Each project is analysed with respect to five dimensions and in terms of its benefits for the organisation under study and, in turn, for KM practice. The analysis forms an empirical basis that shows how PAR could play an important role in tackling some of the acknowledged obstacles to effective KM practice and to furthering KM theory. 
This paper identifies common ground between the processes of KM and PAR and opens up the opportunity to suggest that they can inform each other; the emphasis herein is on the contribution of PAR practice to KM practice. However, the reciprocity between KM and PAR presents researchers and KM practitioners with a 'win-win' situation; not only can researchers inform organisational KM practice in line with the thrust of the arguments presented here, and, in turn inform KM theory, but KM practitioners can also inform PAR activities and, in turn, contribute to the theory of research as shown in Figure One.

\section{Figure One. Model of the Interplay between Research and KM}

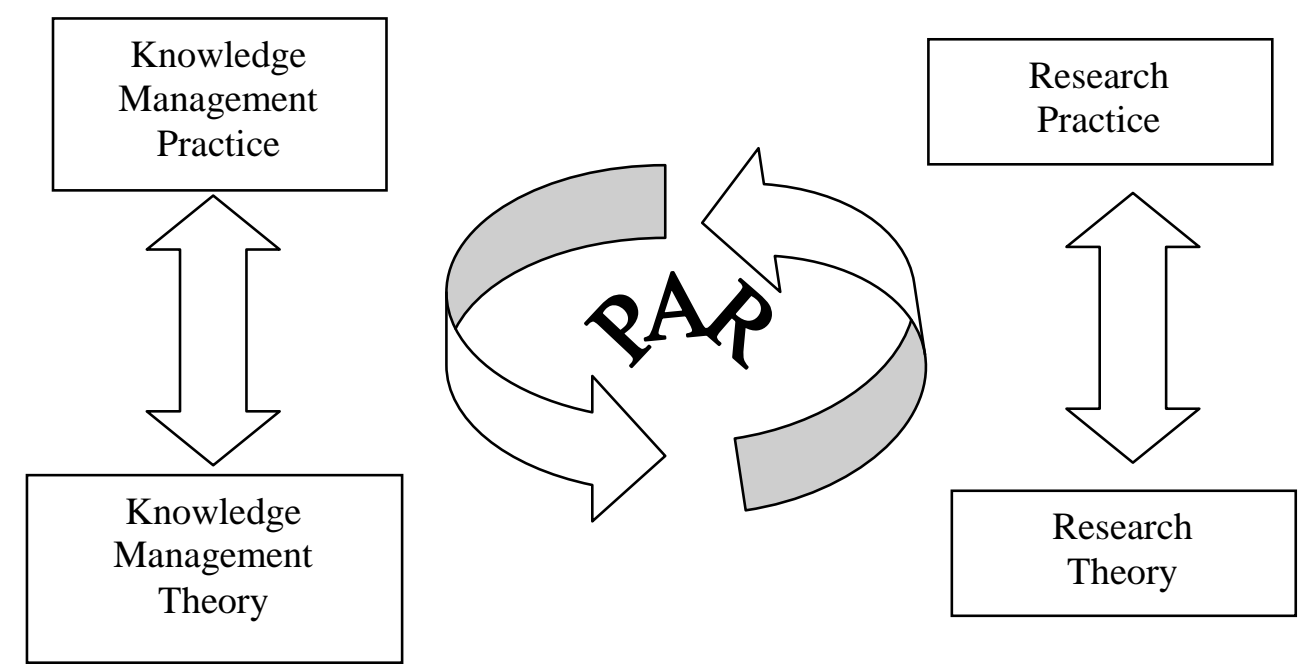

\subsection{A Move from Functionalism to Interpretivism}

The sociological paradigms of Burrell and Morgan (1979) continue to provide a useful framework through which to explore and articulate our understanding of research. On the assumption that within the KM field, there is agreement about seeking to achieve a regulatory process of organisational change (rather than a radical process that emphasises anarchic responses) then it could be argued (through consideration of the nature of reality, ontological and epistemological assumptions, and the nature of human beings) that the dominant mindsets in KM are those expressed as 'functionalist' and 'interpretivist'.

Research in a functionalist paradigm would tend to be undertaken with a high level of objectivity akin to that with which researchers in the natural sciences operate. There would be an emphasis on quantitative methods and a determination to provide rigour and scientific validity. Research methods applied in this paradigm would tend to be highly structured and seek repeatability. On the other hand, in an interpretivist paradigm, research would tend to be undertaken in a more subjective manner analogous to the way in which social scientists operate. There would be an emphasis on qualitative methods and researchers would attempt to take account of the unpredictable nature of human beings while employing relevant methods for the unique scenarios they find themselves in. Research methods utilised in the interpretivist paradigm tend to be less structured and focus more on inquiry rather than deduction and proof. While both paradigms call for critical thinking, one might envisage that researchers working in the functionalist paradigm are more active in hypothesis testing than those whose research is underpinned by the interpretivist paradigm and who are seeking to understand behaviour. 
In a review of the development of various disciplines, Ragsdell (2003) drew attention to the tendency for disciplines to adopt a functionalist stance in their early days, as more tangible aspects of the subject area are tackled. Once some of the 'harder' issues have been dealt with - often with technological 'solutions' - 'softer' issues are given greater priority. These often bring greater challenges for practice since they generally involve social aspects; they also bring more messy topics for research. If research activities are to remain commensurable with the nature of the subject being researched and, thus, remain effective, it is suggested that a more interpretive stance towards research is called for as the discipline develops.

Not too surprisingly, the shift from a functionalist perspective to a more interpretive one aligns with the emergence of new generations of KM that are more concerned with managing tacit, rather than explicit, knowledge and increasingly stress the notions of social interaction and learning, rather than the role of technology (eg McElroy, 2003; McDermott, 1999). So, one might expect to see a similar shift in the dominant stance adopted by KM researchers; likewise for KM practitioners, from an information technology (IT) paradigm to a humanistic one (Gloet and Berrell, 2003).

This does not imply that an interpretivist approach to research in KM is superior or preferable to a functionalist one, or vice versa. Nor does it mean that the paradigms cannot be practised in a complementary manner. Rather, it is about maintaining the effectiveness of the research approach in the light of changing research agendas; it is therefore important that KM research does not become trapped in one paradigm or the other. Edwards' vision for the future of KM research and practice, based on a comprehensive survey of parties interested in KM, alluded to this potential dilemma. In Edwards et al (2003, p59), he aired the following: “...regarding research approaches and theories, my view is that for advancing the KM field we should be more open to different approaches and theories”.

Hislop (2005, p14), in a similar kind of discussion, noted that "While the practice-based perspective, as will be seen, is founded on a critique of the objectivist perspective, the objectivist perspective has by no means been abandoned. In terms of contemporary knowledge management practice and analysis there is evidence that both perspectives are widely used". Moving between the paradigms, whatever language we use to express them, when appropriate, is the secret of effective research. Similarly for KM practice; locking an organisation's KM initiative into one paradigm or the other, runs the risk of overemphasising some aspects and neglecting others.

But moving between paradigms is something that needs to be done consciously and conscientiously. There is evidence of, for example, researchers adopting a quantitative process of analysis to qualitative data and of them declaring their commitment to a particular methodology and then following another (see Kane et al, 2006 for detailed evidence). Equally, there is evidence of practitioners leading a purported 'people-centred' KM strategy and then driving it with technology. While care is needed to avoid the fundamental isolationist and imperialistic traps as defined by Flood and Romm (1996), care is also needed so as to recognise when our movement between paradigms, during research and practice, creates tension in our ways of thinking about and managing knowledge. Not only is greater coherence between our 'espoused paradigm' and our 'paradigm in use' required at a strategic level but also at an operational level. The overarching paradigm of our research strategy and that of its practice should demonstrate commensurability. 


\subsection{Approaches to Research}

While distinguishing between research approaches is not straightforward, a case study approach is now put forward as an example of a predominantly functionalist approach to research while PAR is given as an example of an interpretivist approach (as tabulated by Cornford and Smithson, 1996, p46). Although both of them encourage the use of a range of complementary data collection methods, there are distinct differences between the purposes of each approach and, in turn, between the researcher-stakeholder interactions.

\subsection{Case Study Approach}

Amongst the growing KM literature, case study approaches have been widely adopted (eg Jenner, 2005). Researchers have explored particular aspects of KM in specific settings, in keeping with McNeil's (1990, p87-88) understanding of case studies as an example of social research that is not based on a representative sample. A case-study involves the in-depth study of a single 'unit' - a department, an event or an individual, for example - and may involve the use of quantitative and qualitative research methods. The range of examples of such studies given below reflects diversity in terms of organisational type, sector and geographical location but each case study is scoped around one such 'unit'.

The burgeoning KM literature has spawned case studies from legal settings in Spain (Casanovas et al, 2005) to transport settings in Hong Kong (Cheung et al, 2007) and France (Skok, 2004). Continuing with an international theme, Ergazakis et al (2006) offer a Greek example while Lam (2005) researched in an Indian context. Then there are examples from education such as Chua's (2006) study of a community of practice in a particular college and Biloslavo and Trnavcevic's (2007) development and application of a knowledge audit instrument in a higher education setting. Meanwhile, a healthcare setting was used by Ford and Angermeier (2004). On a larger scale, Oliver and Kandadi (2006) used multiple case studies in a selection of large scale organisations while Marouf's (2007) focus was on 22 units in the chosen organisation.

There is no intention to change the status quo via case study research although the agreed output is often a report that has the potential to influence the future plans and actions of the organisation. In practice, case study research can be positioned anywhere along the applied and pure research spectrum where applied research involves four stages - designing the project, gathering the data, interpreting the findings and recommending actions to the client. During all these stages the researcher acts in the expert role. Alternatively, a case study could fit the profile of pure research which calls for even less interaction with clients; members of the client organisation are treated as passive subjects, merely authorising the project and receiving the results. As will be seen in the next section, the role of the researcher and the interactions between researchers and participants are quite different in PAR.

\subsection{Participatory Action Research (PAR)}

Drawing from Ragsdell (1998, p506), the intentions of PAR and its distinguishing characteristics are presented. Discussion begins with the parent research strategy of action research (AR).

AR is a research strategy that attempts to link theory and practice. It aims to combine the practical concerns of people in problem situations with the goals of social science. PAR is a member of the family of action research. With its roots in applied research, according to Whyte (1991, p7) PAR evolved out of intellectual development and action in the three 
streams of social research methodology, participation in decision making by low ranking people in organisations and socio-technical thinking regarding organisational behaviour. However, in PAR the relationship between the researcher and the clients is very different; some members “..... participate actively with the professional researcher throughout the research process from the initial design to the final presentation of results and discussion of their action implications" (Whyte, Greenwood and Lazes, 1991, p20). The success of this aspect is founded on the Lewinian thought that “...causal inferences about the behaviour of human beings are more likely to be valid and enactable when the human beings in question participate in building and testing them. Hence it \{ie PAR $\}$ aims at creating an environment in which participants give and get valid information, make free and informed choices (including the choice to participate), and generate internal commitment to the results of the inquiry” (Argyris and Schön, 1991, p86).

McNeil (1990, p10) supports this view by stating that "In most social research the researcher aims to be detached and not to affect or interfere with that which is being studied. In action research the researcher is actively involved in planning and introducing some change in policy, and then in using their research expertise to monitor and possibly to evaluate its effect. It is sometimes called 'evaluative research'.” More recently, McTaggart (1999, p496) put forward that "The aim of participatory action research is to change individual and collective practices, social structures, and social media which maintain irrationality, injustice, and incoherent and unsatisfying forms of existence." He goes on to expand the definition of PAR by saying "Participatory action research engages the educational, cultural, and political work required to change practice in sensible and defensible ways." From another perspective, Styhre and Sundgren (2005, p54) "speak of action research as a loosely coupled framework of research methodologies aiming both at producing theoretical insights and practical effects”.

So, PAR is a process that simultaneously aims to bring about change in organisational practices and to increase understanding of social science, through researchers and organisational members working as partners in situations that are perceived to be problematic. It is a relatively new approach to research that offers a different paradigm from that traditionally used in the natural sciences and it is not without inherent difficulties. Styhre and Sundgren (2005) acknowledge the difficulties of experimenting in real life settings without being able to "fully control and determine the environment and the processes of the experiment" (p58) while the additional challenges brought by industry-funded PAR are raised by Breu and Hemingway (2005). Other authors have also drawn attention to some of the obstacles of PAR: de Guerre (2002) draws out lessons for undertaking PAR in a researcher's own organisation and the ethical dilemmas that it creates are raised by Walker and Haslett (2002).

Examples of KM research projects based on action research, let alone PAR, are sparse in comparison to the numbers based on a case study approach. Raman et al (2006) and Pavesi et al (2002) are the two closest examples while Boyd et al's (2004) project is verging on AR given the close proximity with which they were working with participants. A little earlier, Wastell (2001) was practising action research.

\subsection{Research Projects}

In this section, two KM research projects recently undertaken by the author are presented. As will be seen, the first was framed by a case study approach and upheld various functionalist characteristics while the second was embraced by a PAR strategy and reflected more of an 
interpretivist paradigm. Each project is analysed in terms of five selected dimensions and in relation to what benefits it brought for the organisation under study with respect to its KM practice.

\subsection{Research project I - Case Study}

The first research project was an externally funded, 3 month, pilot study into the inhibitors and enhancers to knowledge sharing of a voluntary sector organisation (Ragsdell, 2007). A member of the Board of Trustees of this organisation had sought the expertise of an academic with experience in the voluntary sector who would be willing to input into an organisational review. At the outset, the nature of the input was unclear. However, the author and the organisation's Manager soon agreed upon an investigation into knowledge sharing in the organisation. Research funding was realised to cover the costs of employing a Research Associate (RA).

In keeping with the specified aims and objectives, the project began with a review of recent literature centred on knowledge sharing in a broad range of organisations. This review raised awareness of factors - derived primarily from cultural and technological features of the organisation - that can influence the effectiveness of the knowledge sharing process. These factors were at the heart of the data collection tools - questionnaires and interviews - that were used with a range of organisational stakeholders. Analysis of the collected data surfaced a range of enhancers and inhibitors to knowledge sharing in this organisation; similarities and differences with the literature were evident. A report of the project, including the methodology, empirical data and key findings, was given to the organisation's Manager.

\subsubsection{Role of Researchers}

From the outset, the author had been targeted as an expert of research in the third sector. This immediately brought about responsibilities for her and the RA. Coupled with the funding arrangement (monies were allocated to the university), this meant that the researchers led on all activities and operated somewhat as external consultants. Other than to seek approval from the organisation's Manager on various points e.g. project outline, design and implementation of the data collection tools, and content of the final report, the project team did not conscientiously work with the various stakeholders. As the RA was regularly in attendance at the organisation, she acted as an expert in the use of the designed data collection tools; the author was a point of reference for the organisation's Manager.

\subsubsection{Role of Participants}

Employees, volunteers and members of the Board of Trustees had been identified as potential participants in the project since each of them had a stake in the organisation. They were viewed by the researchers as valuable sources of information that would be elicited by administering questionnaires and undertaking interviews. Stakeholders were not invited to participate further than to respond to the two data collection tools, and feedback on the findings of the project was only given to the organisation's Manager.

\subsubsection{Research Tools}

Traditional data collection tools were utilised as set out in the predefined project outline to compare documented knowledge sharing practices with those experienced in the case study organisation. Questionnaires and interviews were used for primary research with the results being analysed with descriptive statistics and textual analysis.

\subsubsection{Output}


The overarching emphasis of the project was to 'find out' about the situation, there was never an intention to improve the situation. Thus the output from the project was a report of the three months of activities and a summary of the key findings with respect to enhancers and inhibitors to knowledge sharing in this particular third sector organisation.

\subsubsection{Outcomes}

Although 'taking action' was never on the agenda, it does not mean that change has not been brought about by this study. The well known Hawthorne effect is an inevitable consequence of researchers entering an organisation but, without any formal monitoring of 'before' and 'after', no evidenced conclusions can be drawn. However, participants' expectations will undoubtedly have been raised about an improvement in the organisation's knowledge sharing practices. In addition, some may feel that the project enabled them to voice their opinion on this issue and have a 'fair say' while others may not have participated fully and continued to reinforce the status quo. Any potential changes triggered by this project became the organisation's responsibility to manage.

\subsubsection{Benefits for KM Practice in the Organisation}

As a result of this research project, the organisation's Manager became aware of some of the issues in relation to knowledge sharing between the various stakeholders. Good practices and obstacles to effective knowledge sharing were identified to her and it then became her decision as to whether or not, and how, to act on the findings.

\subsection{Research project II - PAR}

The second research project was triggered by an invitation to the author from a UK utility company, to facilitate a process of organisational change. Similar to various other occasions that she had been commissioned to work as a facilitator for this company, it was quickly agreed that this intervention would be treated as PAR with the practical and theoretical concerns as follows. The practical concern of the department was to design a Strategic Asset Management process that would outperform their competitors' equivalent process, while the research concern was how groups of people could use metaphors to manage organisational knowledge.

The focus of the project was a one-day workshop in which all departmental members joined in utilising creative thinking techniques, including metaphors, to generate alternative designs for the specified organisational process. (Details can be found in Ragsdell, 2006). The researcher drew from her area of expertise and from previous experiences to design the workshop. Particular attention was paid to creating a prevailing atmosphere that encouraged and supported participation, systemic thinking, open mindedness and fun since this aligned well with the characteristics of PAR and those required for creative thinking. By the end of the workshop, all participants had contributed to developing a range of options to replace the current organisational process and all were committed to their implementation. Metaphors had played a significant role in the KM cycle with which they had engaged - most evidently in the creation, capture and sharing of knowledge.

\subsubsection{Role of Researcher}

Since, from the outset of the project, the author's role had been defined as that of a facilitator, there was an alignment with the role of a PAR researcher. While facilitative responsibilities meant that she could not participate as fully as the other departmental members, she was able to input suggestions and work closely with them. She was not viewed as an expert who 
would unearth model examples for their organisational process but rather as an enabler to surface the expertise of the departmental staff.

\subsubsection{Role of Participants}

All the departmental members accepted the invitation to join the workshop and all seemed to fully and genuinely participate. Although the contract had been instigated by the Departmental Manager, he too behaved as, and contributed as, an equal participant. All attendees were active players and contributed to the idealised design of the organisational process.

\subsubsection{Research Tools}

The opportunistic nature of the remit and the absence of a requirement to meet an external funding body's criteria, gave greater flexibility to the selection of research methods and tools. In addition to using metaphors to inspire alternative designs as the practical concerns were tackled, processes such as story telling, idealised design and the drawing of 'rich pictures' were undertaken by participants. With respect to addressing the theoretical aspects of the project, the researcher conscientiously observed people as they engaged with the processes and sought verbal feedback at various points; this was a means of operating at a meta - level as she gauged reaction to each activity without disrupting the practical aspects of the project.

\subsubsection{Output}

While it was understood that there was no guarantee of specific outputs from the workshop, a range of designs for the aforementioned organisational process was generated. They were then formatted more conventionally for submission to higher management.

\subsubsection{Outcomes}

The intangibility and spontaneity of outcomes makes them challenging to identify. However, there seemed to be four clear, welcome outcomes from this research project. Firstly, the ethos of the workshop created an overwhelming willingness from participants to implement the designs that they had generated. This was evident in the action plans that were agreed before the workshop closed. Additionally, the activities that had been undertaken appeared to enhance the team dynamics of the department and would, one might expect, improve its every day working. Thirdly, in addition to addressing the specific task of redesigning an organisational process, methods such as storytelling, idealised design and metaphors found a place in the department's problem solving toolkit and would, no doubt, be used in future departmental problem solving processes. Finally, this type of collaboration had cemented a closer relationship between the utility company and the author's academic institute, thus laying the foundations for further collaboration.

\subsubsection{Benefits for KM Practice in the Organisation}

This example of a PAR project promoted a culture that aligns well with one that supports KM processes, particularly those of knowledge creation and knowledge sharing. It especially promoted creative thinking, learning, participation and empowerment. In addition, the PAR process supported social networking, the creation of transparency and trust, ownership and organisational change. It could be claimed that this approach to research supported the development of a knowledge culture.

\subsection{Summary of Research Projects}

From the above analyses it is clear that the two approaches to researching KM upheld different paradigms. The case study reflected a number of functionalist characteristics. For 
example, the researchers acted as experts and organisational members were valued as sources of important information. The research methods that were employed were standard data collection and knowledge elicitation tools, and the output was a written report for the use of the organisational manager. While there were additional outcomes from the study, the research team's remit did not include their monitoring or evaluation. Nor was it within the project scope to manage any changes to KM practices in the organisation either during or beyond the project timescale. On the other hand, the PAR approach was much more interpretivist in nature and called for the researcher to act in a facilitative role to enable organisational members to generate, share and use their individual and collective expertise. The research methods that were used were drawn from a collection of creative techniques as well as traditional observation and feedback collection methods. The output was a set of designs that would be implemented by the various stakeholders and the various identifiable outcomes would support future development of the organisation. In addition, findings from the project have been disseminated amongst the academic community.

\subsection{The Contribution of PAR to Effective KM Practice}

The research projects described above were both research projects about KM. The former focussed on identifying inhibitors and enhancers to knowledge sharing while the latter was more concerned with understanding the application of tools for knowledge creation, capture, sharing and use. The benefits described for each project have arisen from the research approach that was adopted - similar benefits would probably have arisen regardless of the topic of the research. In this penultimate section, these benefits are related directly to the overcoming of obstacles encountered in the implementation of $\mathrm{KM}$ strategies and $\mathrm{KM}$ practices. Attention is drawn to the role that PAR could play in overcoming obstacles such as those associated with developing a KM culture and the barriers to knowledge sharing. These are well recognised obstacles that have been the centre of debate for the last decade. The contribution that PAR could make in managing the relationship between KM and innovation is also introduced.

\subsection{Developing a KM culture}

As the focus of KM has moved away from technological issues, softer issues have come to the fore. A major area of interest for researchers and practitioners alike is the influence of culture of the success of KM practice. Lam's (2005) work surfaces various cultural obstacles to successfully implementing a KM strategy. He drew attention to the uniqueness of each organisation and expressed the challenges that this brought for the KM practitioner - "The contextual nature of culture means that methods and practices successfully used to address culture issues in one organisation may not produce similar results in other organisations. There are no 'ready made' solutions to cultural problems, so there remains a need to examine culture in KM within different types of organisations.” Lam (2005, p207). Then, from a study of a failed KM initiative at an IT consulting firm in India, Lam (2005, p206) went on to deduce that some of the cultural themes that hindered the initiative were related to internal competitiveness, lack of reward and incentive to engage in knowledge sharing, preference for a face to face mode of knowledge sharing over a tool supported approach and doubts over the quality of knowledge shared by more junior staff.

Adoption of a PAR approach to KM studies in organisations holds the potential to overcome some of these barriers. Firstly, PAR upholds the needs of the organisation and, hence, would not offer an 'off the shelf' set of research methods and tools to either the practical concerns or the theoretical issues - the researcher would be guided by the culture of the organisation in their choice. In fact, since the learning that PAR generates for its participants includes 
learning for the designated researcher, it affords the opportunity for the researcher to gain genuine insights into the organisation and, subsequently, allows for the design and delivery of methods and tools to be adapted as the process progresses. Thus PAR would not work against the organisation's culture; suggestions for improvements would be in keeping with the local culture and, consequently, would have a high chance of successful implementation.

More specifically, as demonstrated by Research Project II, the inclusive nature of PAR can reduce cultural themes of Lam such as internal competitiveness and distinctions between knowledge shared by staff at different levels. In PAR there is a recognition of the value of every stakeholder's contribution to the process that, in a wider context, would support the process of knowledge sharing in the organisation. In parallel, the appreciation of the synergy that is realised when groups of stakeholders share knowledge and recognition of the alignment of personal and organisational agendas would reduce the level of internal competitiveness. The motivation for being active in the knowledge sharing process then changes from external rewards and incentives to intrinsic factors. Thus, the development of a KM culture would seem to be supported by PAR.

\subsection{Promoting Knowledge Sharing}

Building on one of Lam's concerns, an aspect of a KM culture that has been gaining much attention is that of knowledge sharing. In his seminal paper, Riege (2005) categorises knowledge sharing barriers into those at the individual, the organisation and the technological levels. He states that "At an individual or employee level, knowledge-sharing barriers are often related to factors such as lacking communication skills and social networks, differences in national culture, overemphasis of position statuses, and a lack of time and trust” (Riege, 2005, p23). He goes on to identify examples of potential individual barriers to include age differences, gender differences, differences in personal experiences, lack of contact time and interaction between knowledge sources and recipients, use of formal power and a general lack of time to share knowledge.

Again, the participative, inclusive and empowering nature of PAR helps to overcome a significant number of the barriers mentioned above. In their facilitative role, the PAR researcher, can explicitly target some of these barriers as they seek to adhere to the principles of the process. As seen in the example from Ragsdell (2006), the scheduling of the workshop overcame the barrier of a 'lack of time to share knowledge' since the event legitimised the sharing of knowledge, In addition, it promoted the development of social networks and, by acknowledging all attendees as being 'equal', overcame some of the inhibitions in relation to power, position, culture, gender and age. So, PAR can be very powerful in promoting and sustaining knowledge sharing processes.

\subsection{Emphasising KM and Innovation}

The need to manage the relationship between KM and innovation remains high on the agenda of KM practitioners. Gurteen (1998, p5) wrote "Creativity and innovation concern the process of creating and applying new knowledge. As such, they are at the very heart of Knowledge Management. Knowledge Management, however, is a new discipline and creativity and innovation need to be thought about in this new context.” Not unsurprisingly, given the KM movement was in a 'hard' phase at the time, Gurteen went on to acknowledge the role of technology in breaking down some of the barriers to creativity and innovation the people centred approach that he put forward was 'dialogue' (Gurteen, 1998, p10). In a similar vein but more recently, Snowden (2003, p113) began his position paper by making the statement "Creating the conditions for innovation, along with enabling better decision 
making are to my mind the primary goals or functions of Knowledge Management (KM)." These two authors seem to be implicitly establishing a link with PAR. Gurteen is advocating the coming together of individuals to share ideas and knowledge through participating in 'dialogue' and, hence, is aligned with the notions of learning and participation of PAR. Likewise, Snowden is subconsciously calling for the use of PAR through its principles of empowerment and creative thinking, and through its primary aim to enhance decision making in organisations as identified earlier by Whyte (1991). Indeed he refers to the 'creative surprises' that PAR can bring.

\subsection{Summary}

This paper has contributed to the debate about effective KM research and practice by suggesting that a research strategy of PAR has the potential to assist organisations in overcoming some of the barriers to successful KM implementation. Two research projects based on KM, were used to demonstrate the benefits that a PAR approach can bring in comparison to the more traditional case study approach. PAR will bring benefits for effective KM regardless of the topic of organisational research. Parallels in the objectives of PAR and KM undoubtedly ensured complementarity between the approaches. PAR's characteristics of learning, empowerment, creativity and, of course, participation were seen to bring value to KM practice while the cultural dimension of KM sits comfortably with the PAR ethos.

A decade ago, Ives, Torrey and Gordon, (1998, p273) said “....there are many different interpretations as to what Knowledge Management means and how to best address the emerging questions about how to effectively use its potential power. ......... As industry experience is gained, and academics continue to research this field, there will be increased understanding, and in time - alignment. However, today, this is not the case.” Perhaps PAR is the bridge between the academic and industrial arenas that will aid this alignment.

\section{References}

Argyris, C. and Schön, D., (1991), Participatory action research and action science compared - a commentary. In Whyte, W.F. (Ed.), Participatory Action Research, Sage, California, pp. 85-96.

Biloslavo, R. and Trnavcevic, A. (2007), Knowledge Management Audit in a Higher Educational Institution: A Case Study, Knowledge and Process Management, 14:4, pp. 275286.

Boyd, D., Egbu, C., Chinyio, E., Xiao, H., and Lee, C.C.T. (2004), Audio Diary and Debriefing for Knowledge Management in SMEs, Proceedings of ARCOM Twentieth Annual Conference 2004, Heriot Watt University, pp. 741-747.

Breu, K. and Hemingway, C. (2005), Researcher-Practitioner Partnering in Industry-Funded Participatory Action Research, Systemic Practice and Action Research, 18:1, pp. 437-455.

Burrell, G. and Morgan, G. (1979), Sociological Paradigms and Organisational Analysis, Heinemann, London.

Casanovas, P., Poblet, M., Casellas, N., Contreras, J., Benjamins, V.R. and Blazquez, M. (2005), Supporting Newly-appointed Judges: A Legal Knowledge Management Case Study, Journal of Knowledge Management, 9:5, pp. 7-27.

Cheung, C.F., Li, M.L., Shek, W.Y., Lee, W.B. and Tsang, T.S. (2007), A Systematic Approach for Knowledge Auditing: A Case Study in Transportation Sector, Journal of Knowledge Management, 11:4, pp. 140-158.

Chua, A.Y.K. (2006), The Rise and Fall of a Community of Practice: A Descriptive Case Study, Knowledge and Process Management, 13:2. pp. 120-128. 
Cornford, T. and Smithson, S.pp (1996), Project Research in Information Systems, MacMillan, Basingstoke

De Guerre, D. (2002), Doing Action Research in One's Own Organization: An Ongoing Conversation over Time, Systemic Practice and Action Research, 15:4, pp. 331-349.

Edwards, J.S., Handzic, M., Carlsson, S. and Nissen, M. (2003), Knowledge Management Research and Practice: Visions and Directions, Knowledge Management Research and Practice, 1, pp. 49-60.

Ergazakis, K., Metaxiotis, K., Psarras, J. and Grammatikos, K. (2006). Applying the KnowCis Methodology to a Greek Municipality: A Case Study, Knowledge Management Research and Practice, 4, pp. 293-309

Flood, R.L. and Romm, N.R.A. (1996), Diversity Management: Triple Loop Learning, Wiley, Chichester.

Ford, R. and Angermeier, I. (2004), Managing the Knowledge Environment: A Case Study from Healthcare, Knowledge Management Research and Practice, 2, pp. 137-146

Gloet, M. and Berrell, M. (2003), The Dual Paradigm Nature of Knowledge Management: Implications for Achieving Quality Outcomes in Human Resource Management, Journal of Knowledge Management, 7:1, pp. 78-89.

Gurteen, D. (1998), Knowledge, Creativity and Innovation, Journal of Knowledge Management, 2:1 pp. 5-13.

Hislop, D. (2005), Knowledge Management in Organizations: A Critical Introduction, Oxford University Press, Oxford, UK.

Ives, W., Torrey, B. and Gordon, C. (1998), Knowledge Management: An Emerging Discipline with a Long History, Journal of Knowledge Management, 1:4, pp. 269-274.

Jenner, M. (ed.), (2005). Case Studies in Knowledge Management, Idea Group, Hershey.

Kane, H.C.M., Ragsdell, G. and Oppenheim, C. (2006), Knowledge Management Methodologies, E-Journal of Knowledge Management, 4:2, pp. 141-152.

Lam, W. (2005), Successful Knowledge Management Requires A Knowledge Culture: A Case Study, Knowledge Management Research and Practice, 3, pp. 206-217.

Marouf, L.N. (2007), Social Networks and Knowledge Sharing in Organizations: A Case Study, Journal of Knowledge Management, 11:6, pp. 110-125.

McDermott, R. (1999), Why Information Technology Inspired but Cannot Deliver Knowledge Management, California Management Review, 41:4, pp. 103-117.

McElroy, M. (2003), The New Knowledge Management: Complexity, Learning and Sustainable Innovation, Butterworth Heinemann, Boston.

McNeil, P. (1990), Research Methods, Routledge, London.

McTaggart, R. (1999), Reflections on the Purposes of Research, Action and Scholarship: a Case of Cross-Cultural Participatory Action Research, Systemic Practice and Action Research, 12:5, pp. 493-512.

Oliver, S., and Kandadi, K.R., (2006), How to Develop Knowledge Culture in Organizations: A Multiple Case Study of Large Distributed Organizations, Journal of Knowledge Management, 10:4, pp. 6-24

Pavesi, S., Corso, M. and Boer, H., (2002), Supporting Knowledge Management in Communities of Dispersed Workers: An Action Research Approach, Proceedings of 4th International CINet Conference, Espoo, Finland.

Ragsdell, G. (1998), Participatory Action Research and Critical Creativity, Systemic Practice and Action Research, 11.5, pp. 503-515

Ragsdell, G. (2003), No Need to Reinvent the Wheel? Enhancing Knowledge Management Practice with Critical Systems Thinking in: Edwards, J., (ed.) KMAC Proceedings, OR Society, Aston University, pp. 284-291. 
Ragsdell, G. (2006), The Role of Metaphors in Managing Knowledge for Organisational Change: A Case Study from the Water Industry, International Journal of Knowledge, Culture and Change Management, 6:4, pp. 19-28.

Ragsdell, G. (2007), Inhibitors and Enhancers to Knowledge Sharing: Lessons from the Voluntary Sector, in Remyni, D., (ed.) Proceedings of International Conference on Intellectual Capital, Knowledge Management and Organisational Learning, University of Stellenbosch, SA.

Raman, M., Ryan, T. and Olfman, L. (2006), Knowledge Management System for Emergency Preparedness: An Action Research Study, Proceedings of the $39^{\text {th }}$ Hawaii International Conference on System Sciences.

Riege, A. (2005), Three Dozen Knowledge-Sharing Barriers Managers Must Consider, Journal of Knowledge Management, 9:3, pp. 18-35.

Skok, W. (2004), Knowledge Management: Taxis Parisiens Case Study, Knowledge Management Research and Practice, 2, pp. 147-154.

Snowden, D. (2003), Innovation as an Objective of Knowledge Management. Part 1: The Landscape of Management, Knowledge Management Research and Practice, 1, pp. 113-119.

Styhre, A., and Sundgren, M. (2005), Action Research as Experimentation, Systemic Practice and Action Research, 18:1, pp. 53-65.

Walker, B. and Haslett, T. (2002), Action Research in Management, Systemic Practice and Action Research, 15:6, pp. 523-533.

Wastell, D.G. (2001), Barriers to Effective Knowledge Management: Action Research Meets Grounded Theory (Case Study), Proceedings of the 9th European Conference on Information Systems, Bled, Slovenia, pp. 628-639.

Whyte, W.F. (ed.), (1991), Participatory Action Research, Sage, California.

Whyte, W.F., Greenwood, D.J. and Lazes, P. (1991), Participatory Action Research: through practice to science in social research. In Whyte, W.F. (Ed.), Participatory Action Research, Sage, California, pp. 19-55. 